\title{
The CROWN initiative: journal editors invite researchers to develop core outcomes in women's health
}

\author{
Khalid Khan ${ }^{1}$, Peter O'Donovan ${ }^{2^{*}}$ and On behalf of Chief Editors of Journals participating in The CROWN Initiative \\ listed at the end of this article
}

\begin{abstract}
Clinical trials, systematic reviews and guidelines compare beneficial and non-beneficial outcomes following interventions. Often, however, various studies on a particular topic do not address the same outcomes, making it difficult to draw clinically useful conclusions when a group of studies is looked at as a whole. This problem was recently thrown into sharp focus by a systematic review of interventions for preterm birth prevention, which found that among 103 randomised trials, no fewer than 72 different outcomes were reported. There is a growing recognition among clinical researchers that this variability undermines consistent synthesis of the evidence, and that what is needed is an agreed standardised collection of outcomes - a "core outcomes set" - for all trials in a specific clinical area. Recognising that the current inconsistency is a serious hindrance to progress in our specialty, the editors of over 50 journals related to women's health have come together to support The CROWN (CoRe Outcomes in WomeN's health) Initiative.
\end{abstract}

Keywords: Research design/standards, Treatment outcome, Endpoint determination/standards, Clinical trials, Systematic reviews, Guidelines, Bias (Epidemiology), Evidence-based medicine, Consensus

Clinical trials, systematic reviews and guidelines compare beneficial and non-beneficial outcomes following interventions. Often, however, various studies on a particular topic do not address the same outcomes, making it difficult to draw clinically useful conclusions when a group of studies is looked at as a whole [1]. This problem was recently thrown into sharp focus by a systematic review of interventions for preterm birth prevention, which found that among 103 randomised trials, no fewer than 72 different outcomes were reported [2]. There is a growing recognition among clinical researchers that this variability undermines consistent synthesis of the evidence, and that what is needed is an agreed standardised collection of outcomes - a "core outcomes set" - for all trials in a specific clinical area [1]. Recognising that the current inconsistency is a serious hindrance to progress in our specialty, the editors of over 50 journals related to women's health have come together to support

\footnotetext{
* Correspondence: peter.odonovan@biomedcentral.com

2BMC Series, 236 Gray's Inn Road, London WC1X 8HB, UK

Full list of author information is available at the end of the article
}

The CROWN (CoRe Outcomes in WomeN's health) Initiative (Figure 1).

Development of consensus is required around a set of well-defined, relevant and feasible outcomes for all trials concerning particular obstetric and gynaecologic health conditions, such as preterm birth, incontinence, infertility and menstrual problems. With so many subspecialties involved, this is no easy task. Duplication of effort can be avoided by working with the Core Outcome Measures in Effectiveness Trials (COMET) Initiative, which is working towards core data sets for all medical specialties [3]. Production of trustworthy core outcome sets will require engagement with patients, healthcare professionals, researchers, industry and regulators, and the employment of scientifically robust consensus methods [1]. The data for these core outcome sets, once agreed upon, should be collected in trials and reported in publications as standard practice in the future.

Journal editors now invite researchers to take the lead in beginning this work. What will we do as editors to support them and their colleagues? First, we are drawing 
wide attention to The CROWN Initiative by publishing this editorial in the journals listed below. We shall ensure that the global research community, which includes our many reviewers, is aware of the need for core outcome sets. Submissions which describe development of core outcome sets, if deemed acceptable after peer review, will be effectively disseminated.

Our collaboration is not for enforcing harmony at the expense of innovation. To quote from the COMET home page (www.comet-initiative.org): "The existence or use of a core outcome set does not imply that outcomes in a particular trial should be restricted to those in the relevant core outcome set. Rather, there is an expectation that the core outcomes will be collected and reported, making it easier for the results of trials to be compared, contrasted and combined as appropriate; while researchers continue to explore other outcomes as well." We also expect that as new or superior ways of capturing outcomes emerge, core outcome sets will themselves need updating.

Producing, disseminating and implementing core outcome sets will ensure that critical and important outcomes with good measurement properties are incorporated and reported. We believe this is the next important step in advancing the usefulness of research, in informing readers, including guideline and policy developers, who are involved in decision-making, and in improving evidencebased practice.

\section{Competing interests}

The authors declare that they have no competing interests.

\section{Acknowledgements}

The CROWN Initiative is grateful to James Duffy (Trainee Scientific Editor, BJOG) and Louisa Waite (Assistant Editor, BJOG) for the drafting, revision and coordination required for the preparation of this article.

The CROWN Initiative includes the following journals, in alphabetical order (correct on $13^{\text {th }}$ May 2014, up to date list available at www.crown-initiative.org): 1. Acta Obstetricia et Gynecologica Scandinavica

2. American Journal of Obstetrics \& Gynecology

3. American Journal of Perinatology

4. Archives of Gynecology and Obstetrics

5. Australian and New Zealand Journal of Obstetrics and Gynaecology

6. Best Practice \& Research: Clinical Obstetrics \& Gynaecology

7. Birth: Issues in Perinatal Care

8. BJOG: An International Journal of Obstetrics and Gynaecology

9. BMC Pregnancy and Childbirth

10. BMC Women's Health

11. Climacteric

12. Clinical Obstetrics and Gynecology

13. Clinics in Perinatology

14. Cochrane Menstrual Disorders and Subfertility Group

15. Cochrane Pregnancy and Childbirth Group

16. Contraception

17. Current Opinion in Obstetrics and Gynecology

18. European Journal of Obstetrics \& Gynecology and Reproductive Biology

19. Fertility and Sterility

20. Fetal Diagnosis and Therapy

21. Ginekologia Polska

22. Gynecological Surgery

23. Gynecologic Oncology

24. Gynecologic Oncology Reports

25. Human Fertility

26. Human Reproduction

27. Human Reproduction Update

28. Hypertension in Pregnancy

29. International Journal of Fertility and Sterility

30. International Breastfeeding Journal

31. International Journal of Gynecology \& Obstetrics

32. International Urogynecology Journal

33. Journal of Family Planning and Reproductive Health Care

34. Journal of Gynecologic Oncology

35. Journal of Lower Genital Tract Disease 


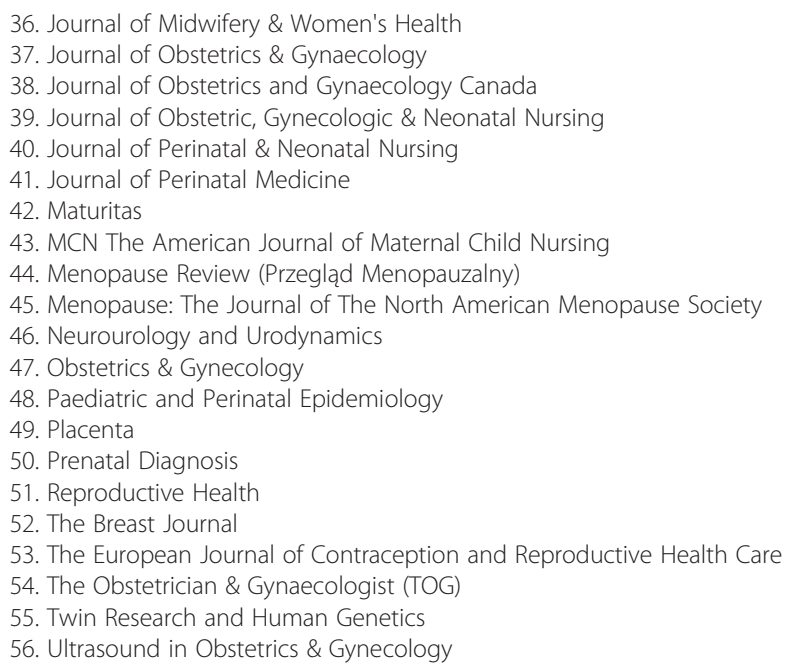

\section{Note}

Reproduced from The Core Outcomes in Women's Health (CROWN) Initiative with permission from the Royal College of Obstetricians and Gynaecologists and John Wiley \& Sons Ltd.

\section{Author details}

'BJOG: An International Journal of Obstetrics and Gynaecology, London, UK.

2BMC Series, 236 Gray's Inn Road, London WC1X 8HB, UK

Received: 29 May 2014 Accepted: 10 June 2014

Published: 23 June 2014

\section{References}

1. Williamson PR, Altman DG, Blazeby JM, Clarke M, Devane D, Gargon E, Tugwell P: Developing core outcome sets for clinical trials: issues to consider. Trials 2012, 13:132.

2. Meher S, Alfirevic Z: Choice of primary outcomes in randomised trials and systematic reviews evaluating interventions for preterm birth prevention: a systematic review. BJOG 2014, doi:10.1111/1471-0528,

3. Williamson PR, Altman DG, Blazeby JM, Clarke M, Gargon E: The COMET (Core Outcome Measures in Effectiveness Trials) initiative. Trials 2011, 12(Suppl 1):A70.

\section{doi:10.1186/1471-2393-14-199}

Cite this article as: Khan and O'Donovan: The CROWN initiative: journal editors invite researchers to develop core outcomes in women's health. BMC Pregnancy and Childbirth 2014 14:199.

\section{Submit your next manuscript to BioMed Central and take full advantage of:}

- Convenient online submission

- Thorough peer review

- No space constraints or color figure charges

- Immediate publication on acceptance

- Inclusion in PubMed, CAS, Scopus and Google Scholar

- Research which is freely available for redistribution 